Supporting Information

\title{
Light-regulated liquid-liquid phase separation for spatiotemporal protein recruitment and cell aggregation
}

Nao Ikeuchi ${ }^{\dagger}$ Takuya Komachi, ${ }^{\dagger}$ Keiji Murayama, ${ }^{\S}$ Hiroyuki Asanuma, ${ }^{\S}$ Atsushi

Maruyama, ${ }^{* \dagger}$ Naohiko Shimada ${ }^{* \dagger}$

${ }^{\dagger}$ Department of Life Science and Technology, Tokyo Institute of Technology, 4259

Nagatsuta-cho, Midori-ku, Yokohama, Kanagawa 226-8503, Japan

${ }^{\S}$ Department of Biomolecular Engineering, Graduate School of Engineering, Nagoya University Furo-cho, Chikusa-ku, Nagoya 464-8603, Japan

E.mails: A. Maruyama: amaruyama@bio.titech.ac.jp

N. Shimada: nshimada@bio.titech.ac.jp 


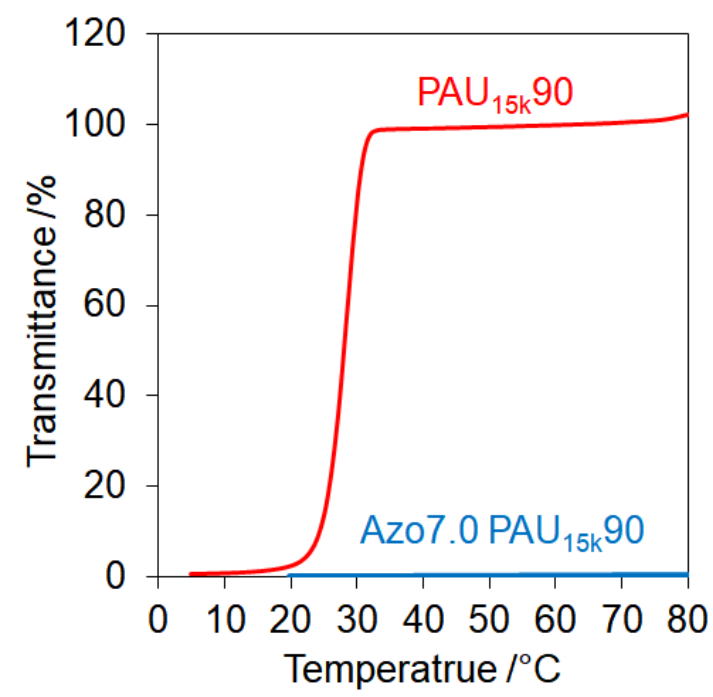

Figure S1 Transmittance curves of PAU $15 \mathrm{k} 90$ (red line) and Azo7.0 PAU15k90(blue line) in $10 \mathrm{mM}$ HEPES-NaOH (pH 7.5) containing $150 \mathrm{mM} \mathrm{NaCl}$. Polymer concentration was $1 \mathrm{mg} / \mathrm{mL}$.

(A)

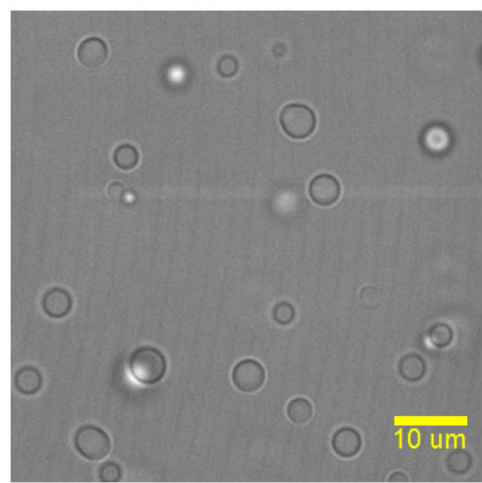

(B)

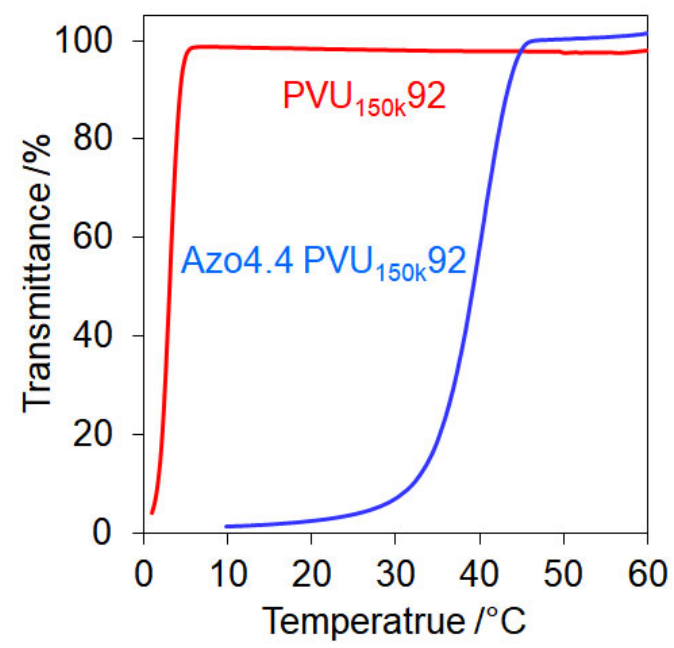

Figure S2 (A) Microscopic image of coacervate-forming Azo4.4 PVU $150 \mathrm{k} 92$ at $25{ }^{\circ} \mathrm{C}$. Scale bar indicates $10 \mu \mathrm{m}$. (B)Transmittance curves of PVU ${ }_{150 \mathrm{k}} 92$ (red line) and Azo4.4 $\mathrm{PVU}_{150 \mathrm{k}} 92$ (blue line). Transmittances were measured at $700 \mathrm{~nm}$. Polymers were dissolved in $10 \mathrm{mM}$ HEPES-NaOH ( $\mathrm{pH} 7.5$ ) containing $150 \mathrm{mM} \mathrm{NaCl}$ at $1 \mathrm{mg} / \mathrm{mL}$. 


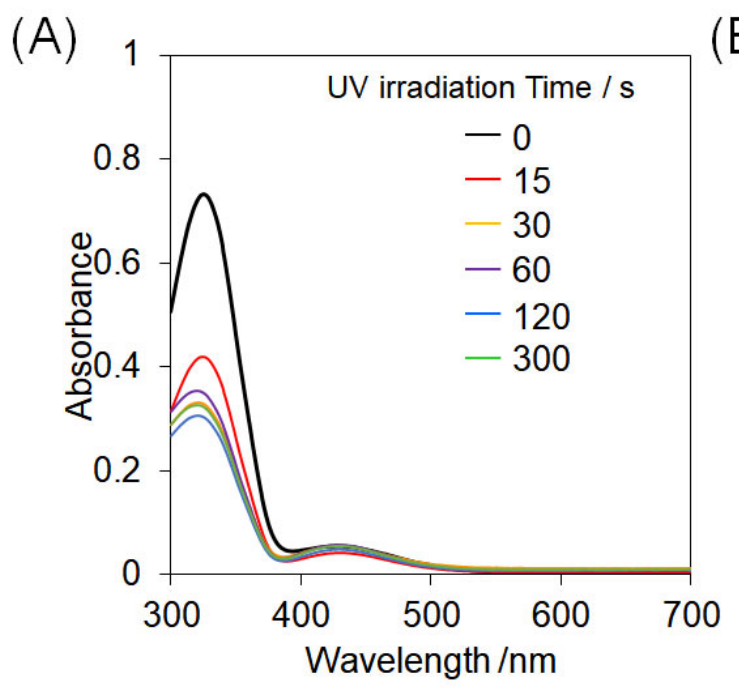

(B)

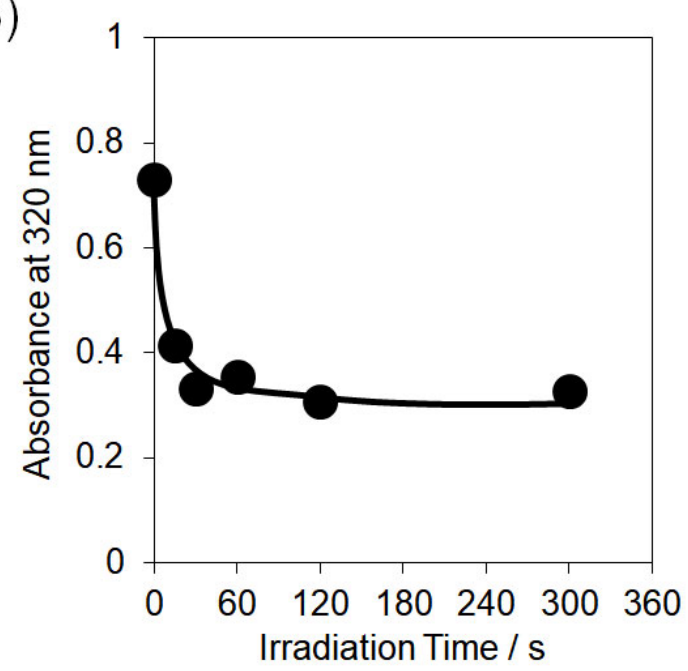

Figure S3 (A)Absorption spectra of Azo4.4 PVU $150 \mathrm{k} 92(0.1 \mathrm{mg} / \mathrm{mL})$ in pure water at various irradiation times. (B)Absorbance at $320 \mathrm{~nm}$ of the polymer as a function of irradiation time.
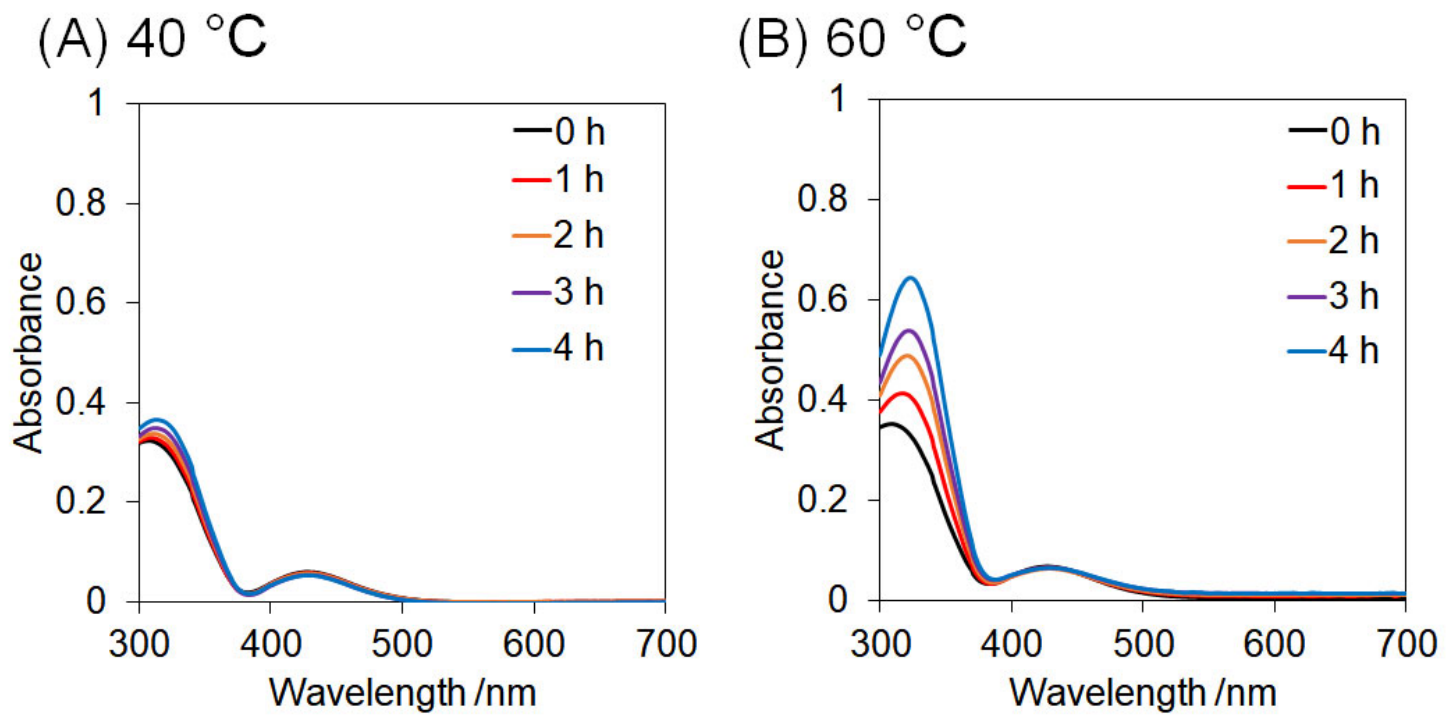

Figure S4 Absorption spectra of UV-irradiated Azo4.0 PVU250k $93(0.1 \mathrm{mg} / \mathrm{mL})$ in pure water. The spectra were measured after incubation for indicated times at $40{ }^{\circ} \mathrm{C}(\mathrm{A})$ or $60{ }^{\circ} \mathrm{C}(\mathrm{B})$. 


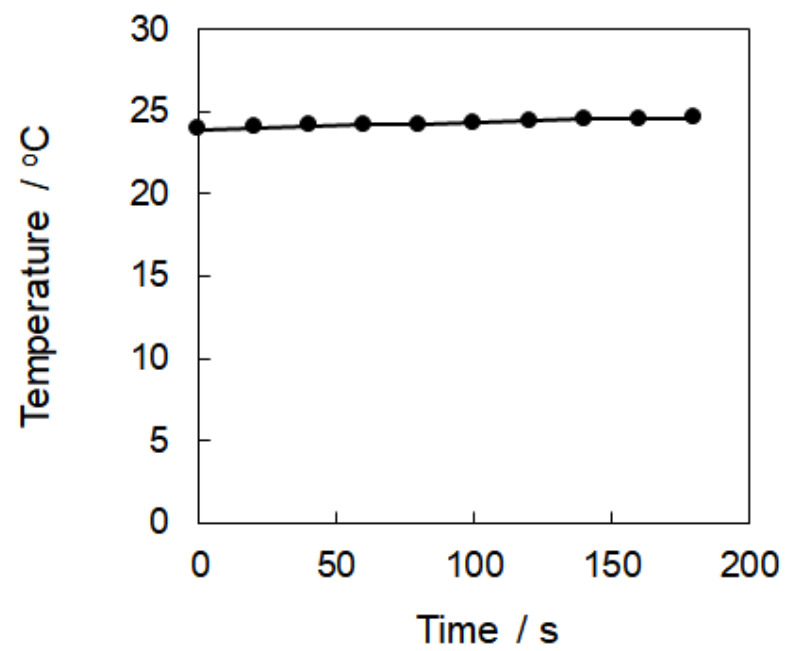

Figure S5 Solution temperatures of Azo4.0 PVU $250 \mathrm{k} 93(4 \mathrm{mg} / \mathrm{mL})$ at various UVirradiation time periods. $372 \mathrm{~nm}$ UV irradiation was carried out under uncontrolled temperature condition.

(A)

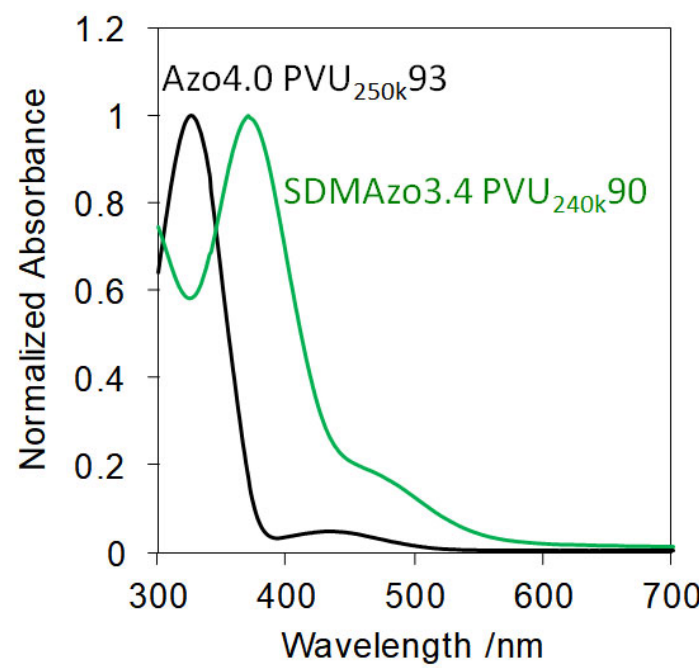

(B)

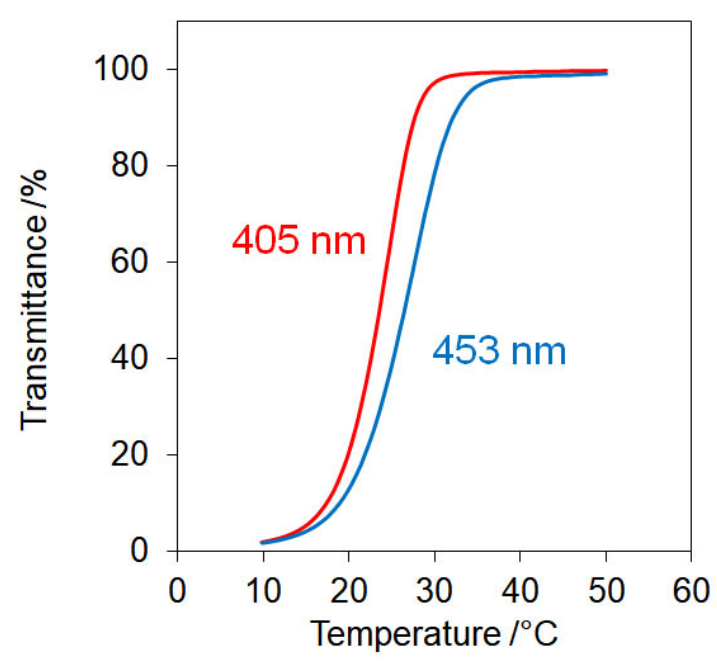

Figure S6 (A)Absorption spectra for Azo4.0 PVU $250 \mathrm{k} 93$ (black line) and SDMAzo3.4 $\mathrm{PVU}_{240 \mathrm{~K}} 90$ (green line) in pure water. (B)Transmittance curves of SDMAzo3.4 $\mathrm{PVU}_{240 \mathrm{~K}} 90(1 \mathrm{mg} / \mathrm{mL})$ in $10 \mathrm{mM}$ HEPES-NaOH $(\mathrm{pH} 7.5)$ containing $150 \mathrm{mM} \mathrm{NaCl}$ after photo-irradiation at $405 \mathrm{~nm}$ (red line) or $453 \mathrm{~nm}$ (blue line). 
(A)

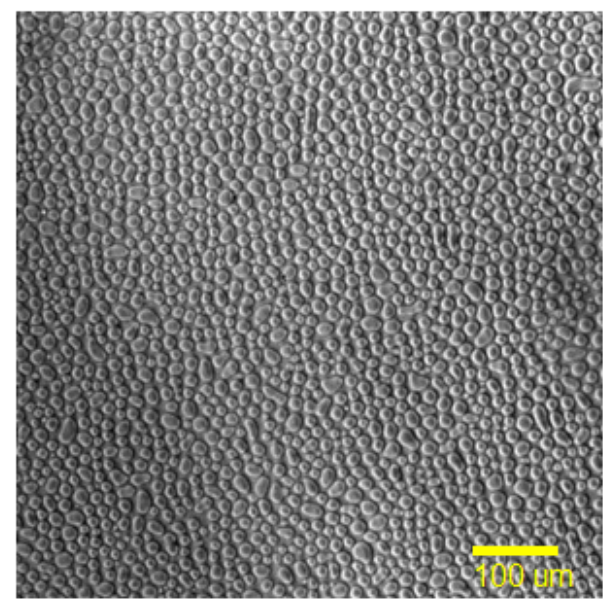

(B)

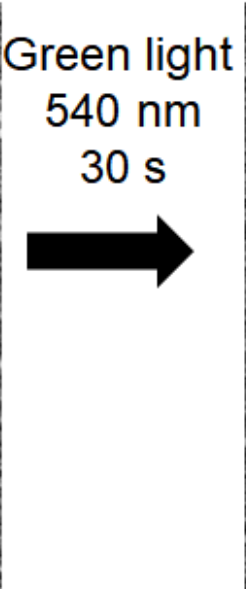

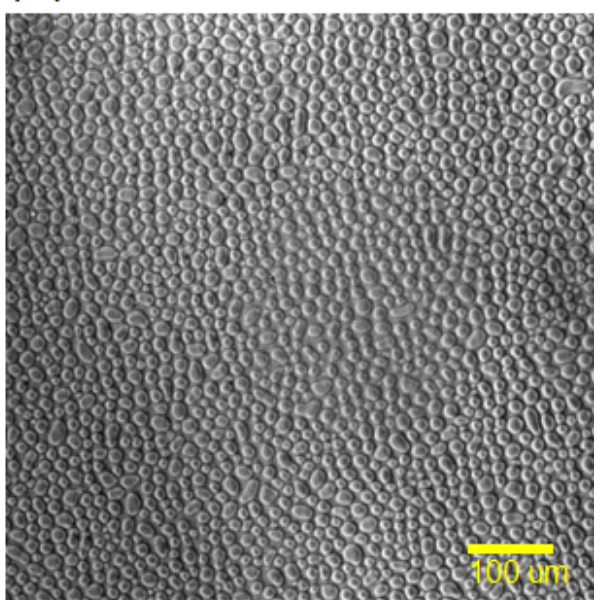

Figure S7 Microscopic images of Azo4.0 PVU250k 93 coacervates deposited on surface of dish in $10 \mathrm{mM}$ HEPES-NaOH (pH 7.5), $150 \mathrm{mM} \mathrm{NaCl}$ at $35^{\circ} \mathrm{C}$. Panel A and B were images for before or after visible-light $(540 \mathrm{~nm})$ irradiation with light condensed by objective lens, respectively. Bars indicate $100 \mu \mathrm{m}$

(A)

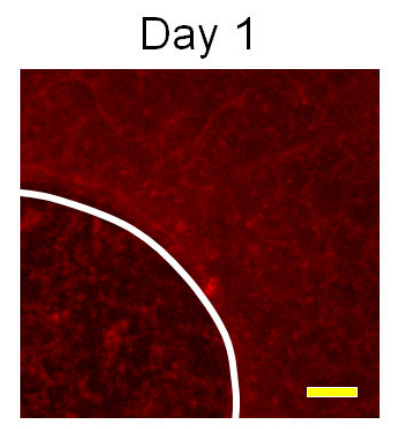

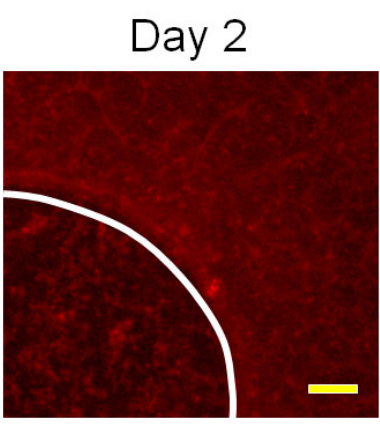

(B)

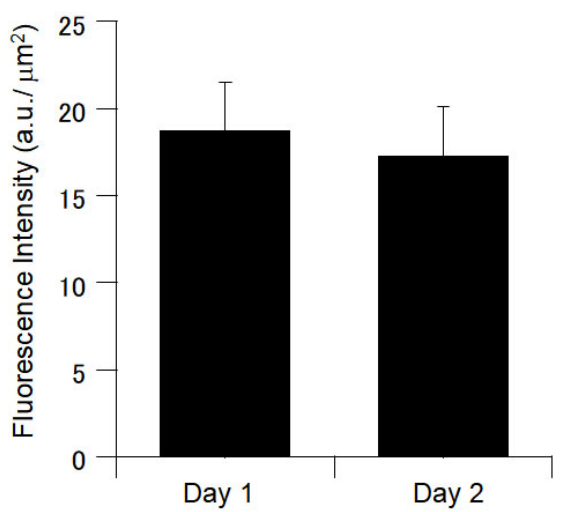

Figure S8 (A)Fluorescence images of captured protein for 1 day (left) and 2 days on surface where coacervate (Azo4.4 PVU210k89) deposition is controlled by UV-irradiation. Area inside white circle was UV irradiated prior to addition of Texas-red labelled BSA $(100 \mu \mathrm{g} / \mathrm{mL})$. Scale bars indicate $10 \mu \mathrm{m}$. (B) Fluorescence intensities on non-irradiated area. 


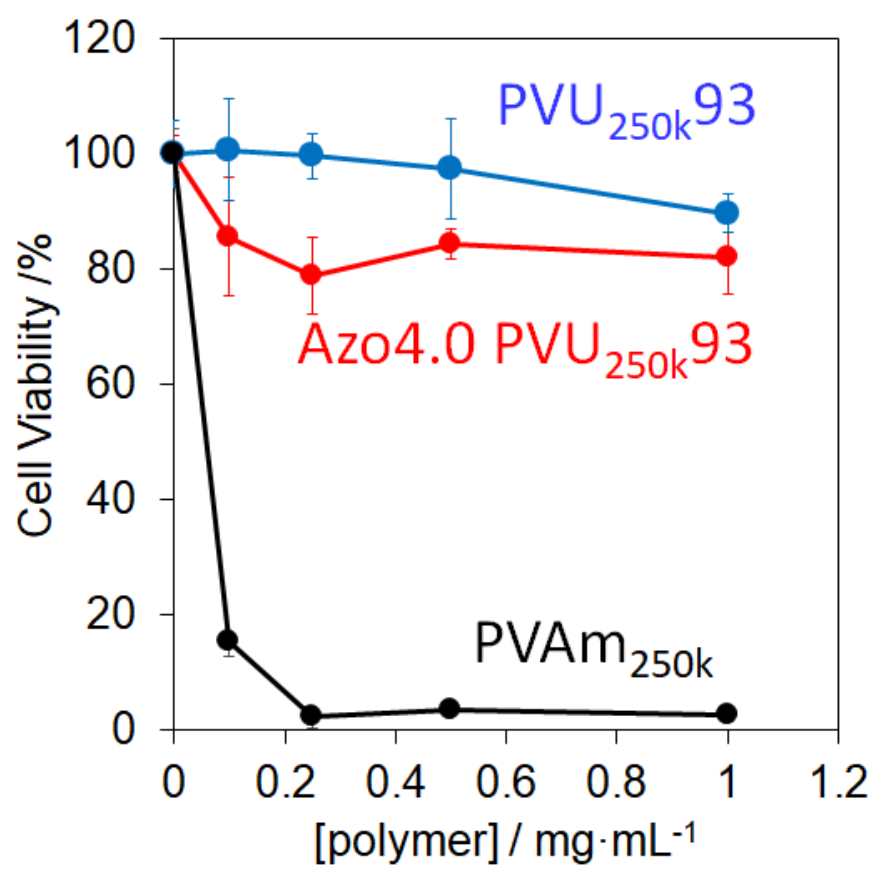

Figure S9 Viability of HeLa cells in the presence of Azo-PVU, PVU or PVAm at various concentrations. Cell viabilities were determined by using the MTT Cell Viability Assay. Values are expressed as mean $\pm \operatorname{SD}(n=6)$ 